\title{
Can student numbers be doubled?
}

\author{
Richard Pearson
}

The reduced numbers of students in higher education likely to result from demographic changes in the 1990s will have to be countered by changes in attainment and participation rates.

LAST month, the Employment column showed how the output of the UK higher education system has trebled over the past three decades and how this expansion continued even through the previous demographic downturn which started in the late $1960 \mathrm{~s}$.

The question for the 1990 s is whether the present output of 120,000 graduates a year can be doubled over the next 25 years as suggested by the Secretary of State for Education.

As a starting point, it is important to recognize that while the decade is ending with shortages of graduates, particularly in technological subjects, a significant number of graduates are unemployed and about one in four say they are underemployed.

The demand for good graduates is expected to increase, although it is not possible to forecast precise numbers or the balance between subjects. If demand continues to grow as it has over the past decade, demand could be 30 per cent higher at the end of the century than it is today.

The number of new graduates is expected to increase by more than 5 per cent by 1992. These students are already on their courses. Thereafter the numbers will depend on staying-on rates in education, examination achievements and the attractions of higher education to the young, particularly women, and to vocationally qualified and mature entrants.

\section{Changes}

Without changes in these factors, demographic change alone within the social classes will reduce the number of entrants to higher education by 10 per cent over the period 1990-2000.

- If, however, educational attainment levels rise by a single percentage point, a rate of improvement faster than that achieved in the 1980 s, then the number of entrants would be four percentage points higher.

- If the A-level attainment rate throughout the United Kingdom were to equal that in Scotland, the numbers would be 31 percentage points higher.

- If the attainment rates of social classes III to $\mathrm{V}$ rise to match those of social classes I and II, the numbers would be 65 percentage points higher.

- If women's participation matches that of men, the numbers should be seven percentage points higher.

- If the participation rate of the vocationally qualified rises to match that of A-level students, the numbers would be 11 percentage points higher.

- Finally, if the participation rate of mature students grows by 50 per cent, the numbers would be 15 percentage points higher in the year 2000 .

\section{Scenarios}

These changes were combined into two scenarios to illustrate what might be achieved in the next decade ${ }^{1}$. The first rising participation - assumes that attainment rates will rise faster than in the 1980 s, participation rates will rise, the number of vocationally qualified entrants will double, the participation rates of mature students will rise by 50 per cent and student loans will not suppress student demand for higher education. Under this scenario, the number of entrants would be 33 percentage points higher in the year 2000.

The alternative scenario, 'constrained expansion', assumes that improvements in attainment rates will continue, but at a rate nearer than of the $1990 \mathrm{~s}$, employer competition for school leavers will reduce participation rates, the number of vocationally qualified will be stable and the mature participation rate will rise by 25 per cent. Under this scenario, all the main factors still show improvements on the $1980 \mathrm{~s}$, but the effect would be only just enough to counteract the demographic downturn, with student numbers in 2000 being the same as in 1990 .

It can be seen that significant changes in attainment and participation rates will be required simply to counteract the demographic effect over the next decade.

To meet the Secretary of State's wish to double student numbers would require changes along the following lines: significant increases in staying-on rates in education at the age of 16 to ensure that A-level attainment rates rise from under 14 per cent to more than 20 per cent, which is almost the level in Scotland; A-level attainment rates of social classes II-V rising by a further half; female participation matching that of males; participation by the vocationally qualified rising significantly to reach the A-level rate; and the mature participation rate increasing by more than 50 per cent.

These represent big improvements on the rates of change seen in the past decade and would result in fewer young people being available for employment in the labour market.

\section{Competition}

Student demand for higher education may, however, be reduced by the growing competition between employers and higher education institutions for the reduced number of school-leavers. Many employers are improving schools liaison and training and career prospects, and are raising salaries in order to maintain school-leaver intakes. They are also widening their recruitment nets to include more women and re-entrants to the labour market. Thus there will be increasing competition to retain pupils in the education system, and to attract both traditional and nontraditional entrants into higher education. The introduction of student loans and a reduction in the size of the maintenance grant is also likely to reduce the short-term attraction of higher education.

The issue for policymakers in higher education, industry and government is how to stimulate student demand and how to organize higher education and provide it with resources to cope with much larger numbers.

Even if student numbers increase, it is likely, assuming that the economy continues to grow, that the demand for good graduates will exceed the supply and that shortages will continue, at least in the first half of the 1990s. Much of this demand will focus on the traditional young graduate with a reasonable class of degree and broad basic skills. Any increase in the supply will include an increasing proportion of nontraditional graduates who, while they may not be 'worse', will be 'different'. A challenge for students, higher education and employers will be to ensure that the attributes of the new supply and the nature of employer demand coincide, otherwise there will be a significant number of graduates who find it difficult to enter what they regard as suitable employment in the 1990 s.

Richard Pearson is at the Institute of Manpower Studies, Mantell Building, University of Sussex, Falmer, Brighton, Sussex BN1 9RF, UK.

1. Pearson, R., Pike, G., Gordon, A. \& Weyman, C. How Many Graduates in the 21st Century? - The Choice is Yours (IMS, Brighton, 1989). 